\title{
PENGARUH STRATEGI PDEODE (PREDICT-DISCUSS-EXPLAIN- OBSERVE-DISCUSS-EXPLAIN) TERHADAP PENGUASAAN KONSEP SISWA PADA MATERI ORGANISASI KEHIDUPAN
}

\author{
Sri Wulan Siti Fatimah, Agus Martono dan Hadiansah \\ Program Studi Pendidikan Biologi, Program Sarjana S1, Universitas Islam Negeri \\ Sunan Gunung Djati Bandung
}

\begin{abstract}
The concept of organizational life in a biology lesson material that requires understanding quite difficult. There fore we need aninnovation that makes student learning is not saturated in an easy to learn and understand a concept PDEODE one of them with a strategy that could potentially broaden and deepen students' conceptual knowledge. The purpose of this study is to determine the effect of the strategy PDEODE student mastery of concepts in the material organization of life. This study departs from the idea that learning the material organization of life with perceived PDEODE strategy would cor respond to the material characteristics of the organization as a strategy PDEODE life is real, it can arouse the curiosity of students, and kontruktivistik so that students can form their own understanding. Through learning by using PDEODE strategy is expected to improve the mastery of student concepts. In this study using Quasi-Experiments with the study population was all students of class VII SMP 1 Atap Cikawao three years of academic classes 2013/2014 and samples in this study were taken two classes with sampling technique used purposive sampling because the research erdiscretion. The instrument used was a test, observation sheets and questionnaires. Test data were analyzed using t-test at the beginning of the test and the Mann-Whitney test at the end of the test and the $\mathrm{N}$-gain. The results obtained on the students mastery of the concept of the experimental class 82.17 and $\mathrm{N}$-gain of 0.72 with high qualifications. Mean while, students mastery of concept son the control class 73.83 and 0.58 with $\mathrm{N}$-gain qualifications being. Mann-Whitney test results obtained on the posttest Zhitung $29>$ Ztabel 1.96 and Mann-Whitney test results on the N-gain obtained Zhitung 6.3> Ztabel 1.96 thus Ho is rejected and $\mathrm{Ha}$ accepted. It is proved that there are significant PDEODE strategy on the concept of student mastery of the material organization of life. This is supported by the percentage of adherence to activity by $95.85 \%$ teachers with excellent qualifications, student activity by $88 \%$ with excellent qualifications and the percentage of student responses at $81 \%$ with very strong qualifications.
\end{abstract}

Keywords: Strategy PDEODE, student mastery of concepts, organizational life.

\section{Pendahuluan}

Perkembangan ilmu pengetahuan dan teknologi (IPTEK) yang sangat pesat telah banyak membawa perubahan pada semua aspek kehidupan manusia. Perubahan tersebut di satu sisi memberikan manfaat bagi manusia itu sendiri dan di sisi lain dapat memberikan dampak yang negatif sebagai akibat dari kemajuan teknologi. Dengan adanya kemajuan di bidang IPTEK ini, maka secara tidak langsung akan terjadi kompetisi dalam segala hal. Hal tersebut menuntut adanya kemampuan sumber daya manusia (SDM) yang berkualitas. Upaya untuk memperoleh SDM yang dapat berkompetisi dalam menghadapi kemajuan IPTEK ditempuh melalui proses pendidikan. Menurut Tirtarahardja (2005), pendidikan adalah suatu proses sadar dan terencana dari setiap individu maupun kelompok untuk membentuk pribadi yang baik dan mengembangkan potensi yang ada dalam upaya mewujudkan cita-cita serta tujuan yang diharapkan. 
Pendidikan formal merupakan salah satu wahana dalam membangun SDM yang berkualitas. Salah satu bagian dari pendidikan formal yang ikut memberi kontribusi dalam membangun SDM yang berkualitas tinggi adalah pendidikan IPA. Pendidikan IPA merupakan suatu usaha yang dilakukan secara sadar untuk mengungkap gejala-gejala alam dengan menerapkan langkah-langkah ilmiah serta membentuk kepribadian atau tingkah laku siswa ke arah yang lebih baik (Hamid, 2011). Hal ini berarti bahwa pendidikan IPA menekankan pada pemberian pengalaman langsung dan kegiatan praktis untuk mengembangkan kompetensi agar siswa mampu menjelajahi dan memahami alam sekitar secara ilmiah. Lebih lanjut Suastra (2009) menyebutkan pembelajaran IPA di sekolah pada hakekatnya terdiri atas tiga komponen yaitu proses ilmiah, sikap ilmiah, dan produk ilmiah. Ketiga komponen ini harus dapat terakomodasi dalam proses pembelajaran IPA di kelas dan/atau di luar kelas. Pendapat ini didukung oleh Bundu (2006), yang menyatakan belajar IPA tidak hanya sekedar penguasaan pengetahuan yang berupa fakta, konsep, prinsip serta hukum tetapi juga merupakan suatu proses penemuan. Oleh karena itu, siswa perlu diberikan kesempatan untuk menggali pemahamannya melalui pengalaman yang diperoleh secara langsung. Akan tetapi, Hamid (2011) mengatakan di Indonesia sendiri belum mampu mengembangkan pembelajaran IPA ke arah tersebut. Berbagai upaya telahdilakukan oleh pemerintah untuk mengatasi permasalahan terkait rendahnya kualitas pembelajaran, khususnya dalam bidang IPA.

Namun dalam kenyataannya, proses pembelajaran IPA di sekolahsekolah belum dapat berlangsung sesuai dengan tuntutan kurikulum yang telah dicanangkan oleh pemerintah. Hal ini dibuktikan dari hasil studi pendahuluan di salah satu SMP di kecamatan Pamulihan, kabupaten Sumedang yang menunjukkan bahwa hasil belajar IPA siswa kelas VII belum optimal yaitu nilai standar ketuntasan minimum 70 sedangkan ratarata nilai siswa 67 . Belum optimalnya hasil belajar IPA yang dicapai siswa salah satunya disebabkan masih rendahnya pemahaman konsep IPA pada siswa. Hal ini diperkuat oleh pendapat Warpala dalam Sekartini (2013:3) yang menyebutkan bahwa pemahaman konsep merupakan prasyarat untuk mencapai pengetahuan atau keterampilan pada tingkat yang lebih tinggi.

Penyebab rendahnya pemahaman konsep IPA yaitu sebagai berikut; Pertama, pola pembelajaran IPA masih bersifat konvensional, dalam arti bahwa dalam kegiatan pembelajaran guru masih mendominasi proses pembelajaran (teacher centered). Kedua, pada proses pembelajaran IPA guru kurang memberikan kesempatan kepada siswa untuk terlibat secara aktif seperti melakukan percobaan, menggunakan alat, mengamati, mengukur, mengumpulkan data, menginterpretasikan data, dan menyimpulkan. Ketiga, pada saat proses pembelajaran IPA guru jarang memperlihatkan fenomena nyata atau media yang berhubungan dengan materi yang dibahas. Hal ini membuat siswa kurang dapat memvisualisasikan konsepkonsep IPA yang sebagian besar masih abstrak. Akibatnya pemahaman konsep IPA siswa menjadi kurang optimal.

Organisasi kehidupan merupakan materi yang cukup sulit bagi siswa, karena materi yang tersaji pada buku-buku paket cenderung abstrak, sedangkan perkembangan mental siswa SMP berada pada fase transisi dari kongkrit ke abstrak. Pengamatan langsung terhadap objek asli, misalnya sel dan jaringan merupakan solusi untuk mengkonkretkan pemahaman siswa terhadap objek tersebut serta memberikan pengalaman belajar yang lebih bermakna.

Bertolak dari permasalahan di atas, maka perlu diterapkan suatu pembelajaran inovatif yang dapat menciptakan suasana pembelajaran yang kondusif dan lebih 
bermakna bagi siswa. Salah satu alternatif yang dapat dilakukan dalam rangka menciptakan iklim pembelajaran yang kondusif adalah dengan menerapkan strategi Pembelajaran Predict-DiscussExplain- Observe- Discuss- Explain (PDEODE). Strategi pembelajaran PDEODE merupakan strategi pembelajaran yang berlandaskan atas teori belajar konstruktivisme. Teori konstruktivisme ini menyatakan bahwa siswa harus menemukan sendiri dan mentransformasikan informasi kompleks, mengecek informasi baru dengan aturanaturan lama dan merevisinya apabila aturan-aturan itu tidak lagi sesuai (Trianto, 2007:13). Berbeda dengan model pembelajaran konvensional yang sudah biasa diterapkan oleh guru di sekolah. Model pembelajaran konvensional didasarkan atas teori belajar behavioristik. Teori belajar behavioristik ini memfokuskan pada hasil belajar tanpa memberikan kesempatan kepada siswa untuk menggali sendiri pengetahuannya, sehingga belajar dilihat sebagai proses meniru dan siswa dituntut untuk dapat mengungkapkan kembali pengetahuan yang sudah dipelajari melalui kuis atau tes terstandar (Winataputra, 2007).

Berdasarkan latar belakang yang dikemukakan, maka tertarik untuk dilakukan penelitian dengan judul "Pengaruh Strategi PDEODE (PredictDiscuss-Explain-Observe-Discuss-

Explain) Terhadap Penguasaan Konsep Siswa Pada Materi Organisasi Kehidupan”.

\section{Metode}

Dalam penelitian ini menggunakan metode Quasi Experimental Design. Di dalam hal ini menggunakan NonequivalentControl Group Design yaitu kelompok eksperimen dan kelompok kontrol tidak dipilih secara acak (random).

Populasi dalam penelitian ini adalah seluruh siswa kelas VII SMPN Satu Atap Cikawao sebanyak tiga kelas tahun akademik 2013/2014 dengan jumlah 90 orang.
Sampel dalam penelitian ini diambil dua kelas dengan teknik sampling Purposive Sampling digunakan karena berdasarkan pertimbangan peneliti. Cara pengambilan sampel populasi yaitu terlebih dahulu diidentifikasi nilai hasil belajar siswa pada semester sebelumnya kemudian diambil nilai yang tertinggi dari kelas yang telah ditentukan. Untuk Sampel yang digunakan dalam penelitian ini adalah kelas VII B sebanyak 30 orang sebagai kelas eksperimen dan kelas VII A sebanyak 30 orang sebagai kelas kontrol.

Metode pengumpulan data dalam penelitian ini menggunakan tes untuk memperoleh data penguasaan konsep siswa berupa tes pilihan ganda sebanyak 20 soal, lembar observasi untuk memperoleh data keterlaksanaan pembelajaran dengan strategi PDEODE, dan angket untuk memperoleh data mengenai respon atau tanggapan siswa terhadap pembelajaran dengan strategi PDEODE.

\section{Hasil dan Pembahasan}

\section{Keterlaksanaan pembelajaran dengan strategi PDEODE}

Pembelajaran dengan strategi PDEODE pada materi organisasi kehidupan terlaksana sangat baik. Hal ini dapat dilihat dari nilai rata-rata untuk aktivitas guru sebesar 95,85\% dengan kualifikasi sangat baik dan nilai rata-rata untuk aktivitas siswa sebesar $88 \%$ dengan kualifikasi sangat baik.Data tersebut dapat pula dilihat dalam bentuk diagram batang pada gambar 1 berikut.

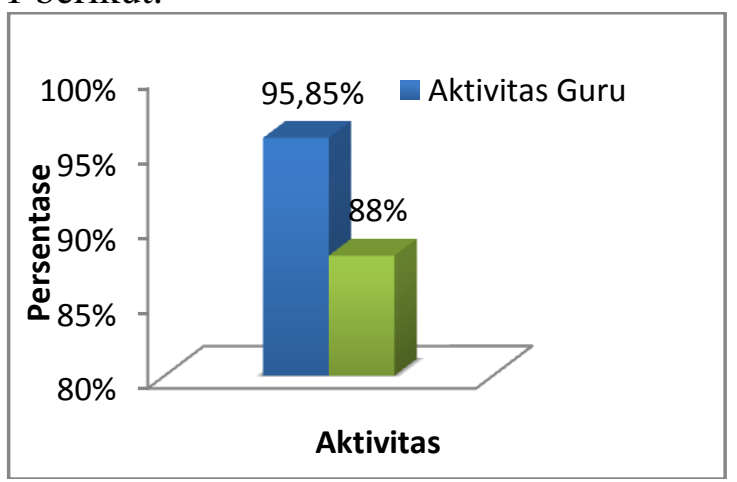


Gambar 1. Diagram Batang Persentase

Rata-rata Aktivitas Guru dan Siswa

Kelas Eksperimen

\section{Penguasaan konsep siswa dengan menggunakan strategi $P D E O D E$}

Hasil analisis rata-rata pretest, postest, dan $N$-Gain yang didapatkan dari siswa kelas eksperimen dalam pembelajaran dengan strategi PDEODE padamateri organisasi kehidupan dapat dilihat pada tabel 1 berikut ini.

Tabel 1 Rata-rata Penguasaan Konsep Siswa dengan Menggunakan Strategi PDEODE

\begin{tabular}{|c|c|c|c|c|}
\hline Nilai & Pretest & Postest & $\begin{array}{c}\boldsymbol{N} \text { - } \\
\text { Gain }\end{array}$ & Kriteria \\
\hline Jumlah & 1170 & 2465 & 21,58 & \multirow{2}{*}{ Tinggi } \\
\hline $\begin{array}{c}\text { Rata- } \\
\text { rata }\end{array}$ & 39 & 82,17 & 0,72 & \\
\hline
\end{tabular}

Pada tabel 1 dapat dilihat bahwa kelas eksperimen memperoleh nilai ratarata pretest 39 , postest 82,17 , dan $N$-Gain sebesar 0,72 dengan kategori tinggi. Tabel tersebut dapat pula dilihat dalam bentuk diagram batang rata-rata penguasaan konsep siswa dengan menggunakan strategi $P D E O D E$ pada gambar 2.

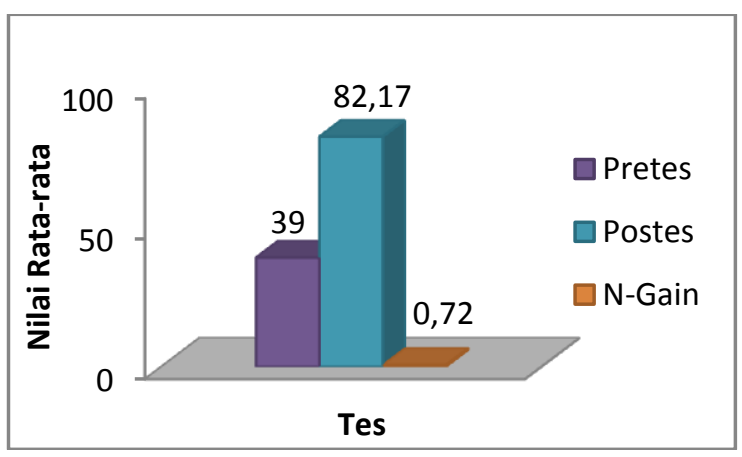

Gambar 2 Diagram Batang Rata-Rata Penguasaan Konsep Siswa Dengan Menggunakan Strategi PDEODE

\section{Penguasaan konsep siswa dengan pembelajaran konvensional}

Hasil analisis nilai rata-rata pretest, postest, dan $\mathrm{N}$-Gain yang didapatkan dari siswa kelas kontroldengan pembelajaran konvensional pada materi organisasi kehidupan dapat dilihat pada tabel 2.

Tabel 2 Rata-rata Penguasaan Konsep Siswa dengan Pembelajaran Konvensional

\begin{tabular}{|c|c|c|c|c|}
\hline Nilai & Pretest & Postest & N-Gain & Kriteria \\
\hline Jumlah & 1145 & 2215 & 17,45 & \\
\cline { 1 - 3 } $\begin{array}{c}\text { Rata- } \\
\text { rata }\end{array}$ & 38,17 & 73,83 & 0,58 & Sedang \\
\hline
\end{tabular}

Pada tabel 2 dapat dilihat bahwa kelas kontrol memperoleh nilai rata-rata pretest 38,17 , postest 73,83 , dan $N$-Gain sebesar 0,58 dengan kategori sedang.Tabel tersebut dapat pula dilihat dalam bentuk diagram batang rata-rata penguasaan konsep siswa dengan menggunakan pembelajaran konvensional pada gambar 5 .

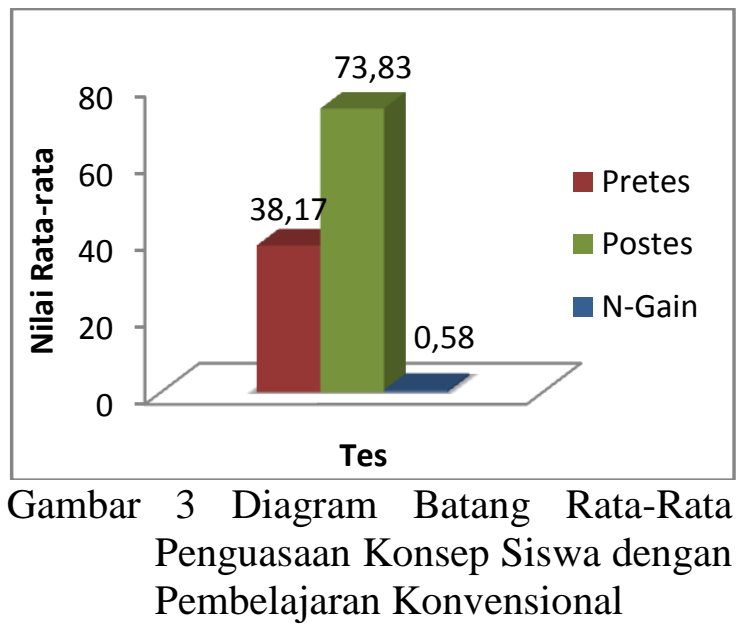

Pengaruh strategi $P D E O D E$ terhadap penguasaan konsep siswa pada materi organisasi Kehidupan

Pengaruh penggunaan strategi PDEODE pada materi organisasi kehidupan pada kelas eksperimen dan pembelajaran tanpa strategi $P D E O D E$ pada kelas kontrol dapat dilihat dari perolehan rata-rata postest dan $\mathrm{N}$-Gain pada kedua kelas yang digunakan. Hasil perhitungan rata-rata nilai postest dan $N$-gain dapat dilihat pada tabel 3 berikut:

Tabel 3 Rata-rata Postest dan N-Gain Kelas Eksperimen dan Kontrol Nilai Rata-rata $\quad$ Interpretasi 


\begin{tabular}{|c|c|c|c|c|}
\hline Kelas & Pretest & Postest & $\begin{array}{c}\boldsymbol{N} \text { - } \\
\text { Gain }\end{array}$ & \\
\hline Eksperimen & 39 & 82,17 & 0,72 & Tinggi \\
\hline Kontrol & 38,17 & 73,83 & 0,58 & Sedang \\
\hline
\end{tabular}

Berdasarkan tabel 3 nilai rata-rata postest dan $\mathrm{N}$-Gain dapat dilihat dalam bentuk diagram batang pada gambar 4 berikut.

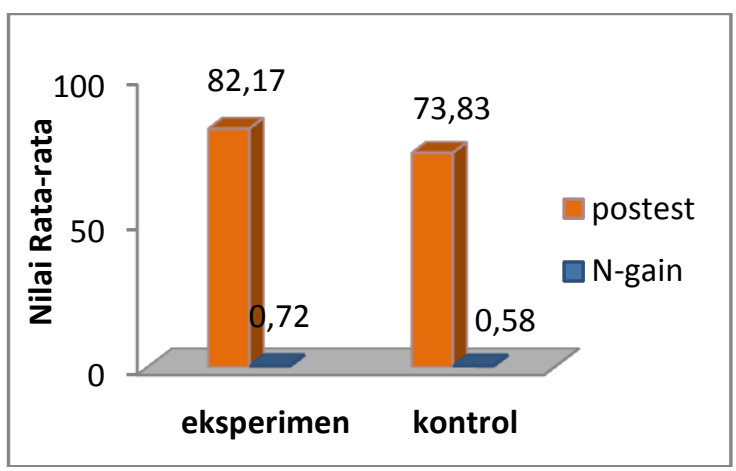

Gambar 4 Diagram Rata-rata Postest dan $N$-Gain Kelas Eksperimen dan Kelas Kontrol

\section{Respon Siswa Terhadap Penggunaan Strategi PDEODE pada Materi Organisasi Kehidupan}

Rata-rata respon atau tanggapan siswa terhadap pembelajaran dengan menggunakan strategi PDEODE pada materi organisasi kehidupan adalah $81 \%$ dengan kualifikasi sangat kuat. lebih jelasnya dapat dilihat pada gambar 5 berikut.

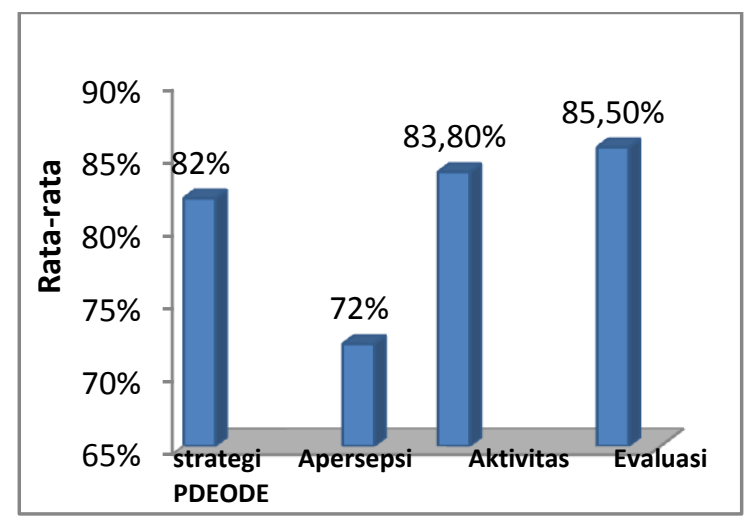

Gambar 5 Diagram Batang Rata-rata Respon Siswa

\section{Pembahasan}

Keterlaksanaan pembelajaran dengan strategi PDEODE diperoleh dari hasil pengamatan terhadap aktivitas guru dan siswa pada setiap tahapan strategi PDEODE. Observasi dilakukan pada kelas eksperimen yang menggunakan strategi PDEODE. Observasi bertujuan untuk mengetahui langkah-langkah selama proses pembelajaran berlangsung. Berdasarkan hasil pengamatan yang dilakukan oleh observer, diketahui bahwa keseluruhan tahapan pembelajaran dengan strategi PDEODE terlaksana dengan sangat baik. Untuk persentase aktivitas guru pada pada pertemuan ke-1 sebesar 91,7\% dengan kualifikasi sangat baik meskipun ada satu aspek yang tidak terlaksana yaitu guru tidak memberikan pertanyaan untuk pemantapan materi, dan pada pertemuan ke-2 mengalami peningkatan menjadi $100 \%$ hal ini karena guru memperbaiki dari proses pembelajaran sebelumnya sehingga proses pembelajaran berjalan dengan lancar. Untuk hasil analisis aktivitas siswa pada pertemuan ke-1 sebesar $82 \%$ dengan kualifikasi baik meskipun ada beberapa aspek yang tidak terlaksana karena siswa masih belum paham terhadap pembelajaran yang dilakukan. Pada pertemuan ke-2 mengalami peningkatan sebesar $12 \%$ menjadi $94 \%$ hal tersebut terjadi karena siswa sudah paham mengenai proses pembelajaran yang telah dilakukan sebelumnya sehingga siswa hanya perlu mengulang proses pembelajarannya. Meskipun seluruh langkah-langkah strategi pembelajaran PDEODE terlaksana tapi dirasakan masih banyak kekurangan yang harus diperbaiki. Kesulitan yang dirasakan diantaranya siswa belum terbiasa dengan strategi $P D E O D E$, selain itu faktor guru sendiri dirasakan belum dapat menguasai kelas dengan baik dan belum dapat mengefisienkan waktu yang tersedia.

Strategi PDEODE dirancang agar siswa aktif mencari sendiri pengetahuannya berdasarkan pengetahuan dan pengalaman yang telah dimiliki sehingga diharapkan dapat meningkatkan 
penguasaan konsep siswa. Berdasarkan hasil analisisyang didapatkan dari siswa kelas eksperimen dalam pembelajaran dengan strategi PDEODE pada materi organisasi kehidupan diketahui setiap indikator mengalami peningkatan, dengan jumlah nilai rata-rata pretest seluruh indikator sebesar $47,73 \%$ dengan kualifikasi kurang sekali dan jumlah nilai rata-rata postest sebesar $80,31 \%$ dengan kualifikasi baik.Adapun berdasarkan pencapaian indikator tertinggi terdapat pada indikator mengingat (C1) yakni $90 \%$ dengan kualifikasi baik sekali, sedangkan pada pencapaian terendah terdapat pada indikator mengevaluasi (C5) yakni 70\% dengan kualifikasi cukup. Adapun hasil analisis nilai rata-rata pretes, postes, dan $N$-Gain yang didapatkan yaitu rata-rata pretest sebesar 39, rata-rata postest sebesar 82,17 . Hal tersebut menunjukkan adanya perubahan penguasaan konsep siswa antara sebelum diberikan perlakuan dan setelah diberikan perlakuan dengan nilai rata-rata $N$-Gain sebesar 0,72 dengan kategori tinggi.

Berdasarkan hasil analisisyang didapatkan dari siswa kelas kontrol dengan pembelajaran konvensional pada materi organisasi kehidupan diketahui setiap indikator mengalami peningkatan, dengan jumlah nilai rata-rata pretest seluruh indikator sebesar $46,76 \%$ dengan kualifikasi kurang sekali dan jumlah nilai rata-rata postest sebesar $74,76 \%$ dengan kualifikasi cukup.Adapun berdasarkan pencapaian indikator tertinggi terdapat pada indikator mengingat $(\mathrm{C} 1)$ yakni $85 \%$ dengan kualifikasi baik, sedangkan pada pencapaian terendah terdapat pada indikator menganalisis (C4) dan mengevaluasi (C5) yakni $66,67 \%$ dengan kualifikasi cukup. Adapun hasil analisis nilai rata-rata pretest untuk kelas kontrol sebesar 38,17 dan nilai rata-rata postest sebesar 73,83. Hal tersebut menunjukkan adanya perubahan penguasaan konsep siswa antara sebelum diberikan perlakuan dan setelah diberikan perlakuan dengan nilai rata-rata $N$-Gain sebesar 0,58 dengan kategori sedang.

Berdasarkan data hasil penelitian yang dilakukan di SMPN Satu Atap Cikawao Kabupaten Sumedang dapat disimpulkan bahwa penggunaan strategi PDEODE yang dikembangkan mempengaruhi kemampuan penguasaan konsep siswa dan layak untuk digunakan dalam proses belajar mengajar. Hal ini ditunjukan dengan hasil uji Mann-Whitney pada postest didapatkan $Z_{\text {hitung }} 29>$ $\mathrm{Z}_{\text {tabel }} 1,96$ dan hasil uji Mann-Whitney pada $N$-gain didapatkan $\mathrm{Z}_{\text {hitung }}$ 6,3> $\mathrm{Z}_{\text {tabel }} 1,96$. Dengan demikian hasil dari proses belajar dengan menggunakan strategi PDEODE meningkat. Dalam suatu penelitian yang dilakukan oleh Bayram Costu (2008), strategi pembelajaran PDEODE sangat efektif digunakan dalam membantu siswa untuk memahami konsep-konsep yang dihubungkan dengan fenomena kehidupan sehari-hari. Selain itu, Kalori et.al. (2005) menyebutkan bahwa pemberian strategi PDEODE secara terus menerus mampu memberikan umpan baluk positif dan mengembangkan pembelajaran ke arah student centered, yang memberikan kesempatan kepada siswa berperan aktif dalam proses pembelajaran serta mampu memberikan pengaruh positif terhadap pemahaman konsep siswa.

Hasil penelitian yang diperoleh mengenai tanggapan atau respon siswa terhadap strategi pembelajaran PDEODE pada materi organisasi kehidupan memperoleh nilai rata-rata pada aspek strategi pembelajaran PDEODE sebesar $82 \%$, apersepsi sebesar $72 \%$, aktivitas sebesar 83,8, dan evaluasi sebesar 85,5. Dengan skor rata-rata keseluruhan adalah $81 \%$ dengan kualifikasi sangat kuat. Hal ini menunjukkan penggunaan strategi PDEODEdapat diterima dengan baik oleh siswa

Pembelajaran dengan model pembelajaran $P D E O D E$ dapat menciptakan pembelajaran yang lebih realistis dan bermakna sehingga berpengaruh terhadap penguasaan konsep siswa. Meskipun 
model pembelajaran $P D E O D E$ telah dapat meningkatkan penguasaan konsep siswa, namun masih ada beberapa kendala dalam penerapan model pembelajaran PDEODE di sekolah. Pertama, siswa belum terbiasa belajar dengan model pembelajaran PDEODE. Siswa belum bisa bereksplorasi secara mandiri dan belum mampu menunjukkan sikap percaya diri dalam memecahkan suatu permasalahan. Kedua, siswa belum terbiasa belajar dengan difasilitasi LKS PDEODE. Pada LKS PDEODE tersebut menuntut siswa untuk mengemukakan pengetahuan awal yang dimiliki dalam menyelesaikan permasalahan yang telah diberikan melalui kegiatan praktikum. Dalam hal ini siswa belum terbiasa untuk merancang alat dan bahan sehingga sering mengalami kesulitan melakukan praktikum. Ketiga, peralatan praktikum yang kurang memadai juga menjadi kendala dalam melaksanakan praktikum yang telah dirancang.

Mengingat kendala-kendala yang dialami dalam pembelajaran dengan strategi PDEODE, maka peran guru sebagai fasilitator, mediator, dan motivator sangat diperlukan dalam membimbing siswa untuk mencapai tujuan pembelajaran yang optimal. Berdasarkan temuan-temuan dan pembahasan terkait dengan keefektifan strategi pembelajaran $P D E O D E$ terhadap penguasaan konsep IPA, maka diyakini strategi pembelajaran PDEODE sangat cocok diterapkan pada pembelajaran IPA.

\section{Kesimpulan dan Saran Kesimpulan}

Berdasarkan hasil penelitian dan pembahasan yang telah diuraikan, dapat ditarik simpulan sebagai berikut:

Penguasaan konsep siswa pada materi organisasi kehidupan dengan menggunakan strategi PDEODE didapatkan nilai rata-rata pretest seluruh indikator sebesar $47,73 \%$ dengan kualifikasi kurang sekali dan jumlah nilai rata-rata posttest seluruh indikator sebesar $80,31 \%$ dengan kualifikasi baik. Adapun hasil nilai rata-rata pretes 39 , postes 82,17 , dan $N$-Gain sebesar 0,72 dengan kategori tinggi.

Penguasaan konsep siswa pada materi organisasi kehidupan dengan pembelajaran konvensional didapatkan nilai rata-rata pretest seluruh indikator sebesar $46,76 \%$ dengan kualifikasi kurang sekali dan jumlah nilai rata-rata postest sebesar 74,76\% dengan kualifikasi cukup. Adapun nilai rata-rata pretest sebesar 38,17 , postest sebesar 73,83 dan nilai ratarata $N$-Gain sebesar 0,58 dengan kategori sedang.

Pengaruh strategi PDEODE terhadap penguasaan konsep siswa pada materi organisasi kehidupan ditunjukan dengan nilai $Z_{\text {hitung }} 29>Z_{\text {tabel }} 1,96$.

Respon siswa terhadap penggunaan strategi $P D E O D E$ pada materi organisasi kehidupan didapatkan skor rata-rata keseluruhan adalah $81 \%$ dengan kualifikasi sangat kuat. Hal ini menunjukkan penggunaan strategi PDEODEdapat diterima dengan baik oleh siswa.

\section{Saran}

Saran yang dapat disampaikan berdasarkan hasil penelitian yang telah dilaksanakan adalah sebagai berikut:

$$
\text { Bagi guru dapat }
$$

mengimplementasikan strategi pembelajaran PDEODE dalam pembelajaran di sekolah sebagai alternatif untuk meningkatkan pemahaman konsep siswa dan dalam pembelajaran guru perlu mengoptimalkan perannya sebagai fasilitator, mediator, dan motivator bagi siswa. Bagi siswa disarankan melatih dirinya untuk lebih aktif mengkonstruksi pengetahuan berdasarkan pengetahuan yang telah dimiliki.Bagi peneliti lain yang berminat mengadakan penelitian lebih lanjut mengenai strategi pembelajaran PDEODE dalam bidang ilmu IPA maupun bidang ilmu lainnya, agar memperhatikan kendala-kendala yang telah dialami dalam penelitian ini sebagai bahan pertimbangan untuk perbaikan dan penyempurnaan penelitian yang akan dilaksanakan.

\section{Daftar Pustaka}


Bundu, P. 2006. Penilaian Keterampilan Proses dan Sikap Ilmiah Dalam Pembelajaran Sains-SD. Jakarta: Departemen Pendidikan Nasional, Direktorat Jenderal Pendidikan Tinggi.

Costu, B. 2008. Learning Science Trhough The PDEODE Teaching Strategy: Helping Students Make Sense Of Everyday Situations. Eurasia Journal of Mathematics, Science \& Technology Education. 4(1). 39. Tersedia pada http://www. ejmste. com/v4n1/Eurasia_v4n1_ Costu. pdf. Diakses pada tanggal 7 jauari 2014.

Hamid. 2011. Pengertian Pendidikan IPA dan Perkembangannya. Tersedia pada http://zaifbio. wordpress.com/2010/04/29/penge rtian- pendidikan- ipa- dan perkembangannya/.Diakses pada tanggal 7 januari 2014.

Kolari. 2005. Enhancing Engineering Students Confidence Using Interactive Teaching Metdhods Part 2: pos-test results for the Force Concept Inventory showing enhanced donfidence. World transctions on engineering and tehnology education. 4(1). 15-20. Tersedia pada http://www.eng.edu.au/uicee.

Diakses pada tanggal 10 januari 2014

Sekartini, dkk. 2013. Pengaruh Model Pembelajaran PDEODE terhadap Pemahaman Konsep IPA siswa kelas IV SD Gugus XII Kec. Buleleng: tersedia pada http://ejournal.undiksha.ac.id/inde x.php/JJPGSD/article/viewFile/68 2/556.diakses: 11 januari 2014

Suastra. 2009. Pembelajaran Sains Terkini. Singaraja: Universitas Pendidikan Ganesha.

Subana. 2000. Statistik Pendidikan. Bandung: Pustaka Setia

Sugiyono. 2009. Statistika Untuk Penelitian. Bandung: Alfabeta
Sutikno, Sobry. 2008. Belajar dan Pembelajaran. Bandung: Prospect.

Suripto. 1990. Diklat Struktur Hewan. Bandung :Biologi ITB

Tirtarahardja. 2005.2 Pengantar Pendidikan. Jakarta: Rineka Cipta.

Trianto. 2007. Model-Model Pembelajaran Inovatif Berorientasi Konstruktivistik. Jakarta: Prestasi Pustaka.

Winataputra, dkk. 2007. Teori Belajar dan Pembelajaran. Jakarta: Universitas Terbuka. 